CASE REPORT

\title{
Failure of intravascular ultrasound to identify the site of recurrent focal coronary spasm during stenting
}

\author{
T Azeem, D Adlam, A Gershlick
}

Heart 2004;90:e33 (http://www.heartjnl.com/cgi/content/full/90/6/e33). doi: 10.1136/hrt.2004.034199

Focal coronary spasm is often associated with an area of mural plaque disease. This report describes a patient with recurrent severe coronary spasm unresponsive to medical treatment. Coronary arteriography and intravascular ultrasound identified a candidate area of minor coronary atheromatous disease but ergonovine provocation testing showed the spastic coronary segment to be distal to and distinct from this area. Coronary stenting of the site identified by ergonovine provocation testing was effective in relieving provoked and spontaneous spasm.

$\mathrm{P}$ atients with severe recurrent coronary spasm unresponsive to medical treatment may respond to stenting of the spastic coronary segment. ${ }^{1-4}$ The site of spasm is often associated with an area of mural atheromatous plaque. Intravascular ultrasound (IVUS) may be used to identify the site of non-stenotic mural plaque, but spasm provocation testing is necessary to identify the spastic coronary segment for stent deployment.

\section{CASE REPORT}

A 54 year old woman presented to the outpatient clinic of a district general hospital with a five week history of chest pain unrelated to exertion. The pain was central and radiated to the left arm. Symptoms usually occurred in the early hours of the morning, lasting for one or two hours with spontaneous relief. The frequency of chest pain had progressed from two episodes a week to daily. She had a medical history of asthma and controlled hypertension for which she was prescribed salbutamol and fludrocortisone inhalers and enalapril $20 \mathrm{mg}$ once daily. She had recently undergone endoscopy to investigate symptoms of dysphagia, with normal results.
Clinical examination in the outpatient clinic was normal Twelve lead ECG showed symmetrical $\mathrm{T}$ wave inversion in chest leads V2-V4 (fig 1). An exercise tolerance test was carried out in the clinic. The patient exercised for over nine minutes with no chest pain. There was pseudonormalisation of the inverted $\mathrm{T}$ waves on exercise but no other new ECG changes. Transthoracic echocardiography was normal. The patient was started on clopidogrel $75 \mathrm{mg}$, long acting diltiazem $200 \mathrm{mg}$, simvastatin $20 \mathrm{mg}$, and a glycerine trinitrate spray. She was referred for early outpatient coronary angiography.

Eighteen days later she presented to the emergency room after an episode of more severe chest pain. The ECG showed no new changes. Troponin T was $0.2 \mathrm{ng} / \mathrm{ml}$ (laboratory range $<1.10$ ) and myoglobin was $63 \mathrm{ng} / \mathrm{ml}$ (laboratory range $<70)$. Inpatient stress echocardiography showed no wall motion abnormality at dobutamine doses up to $40 \mu \mathrm{g} / \mathrm{kg} / \mathrm{min}$. In view of this finding it was felt that there was a low probability of fixed stenotic coronary artery disease. The patient was started on a proton pump inhibitor and discharged. One month later she presented again with severe chest pain. This time a 12 lead ECG undertaken by her primary care physician showed anterior ST segment elevation. This had settled by the time she was admitted to hospital. She was started on intravenous nitrate and unfractionated heparin. Despite this she had two further episodes of chest pain with associated ST segment change over the next 24 hours. The troponin $\mathrm{T}$ concentration was $10.3 \mathrm{ng} / \mathrm{ml}$. The decision was taken to transfer the patient to the tertiary cardiac intervention centre for angiography.

Coronary angiography was performed. This showed no flow limiting coronary stenoses, although there was minor disease in the mid left anterior descending artery (LAD). A clinical diagnosis of recurrent spontaneous coronary spasm was made and over the next two weeks attempts were made

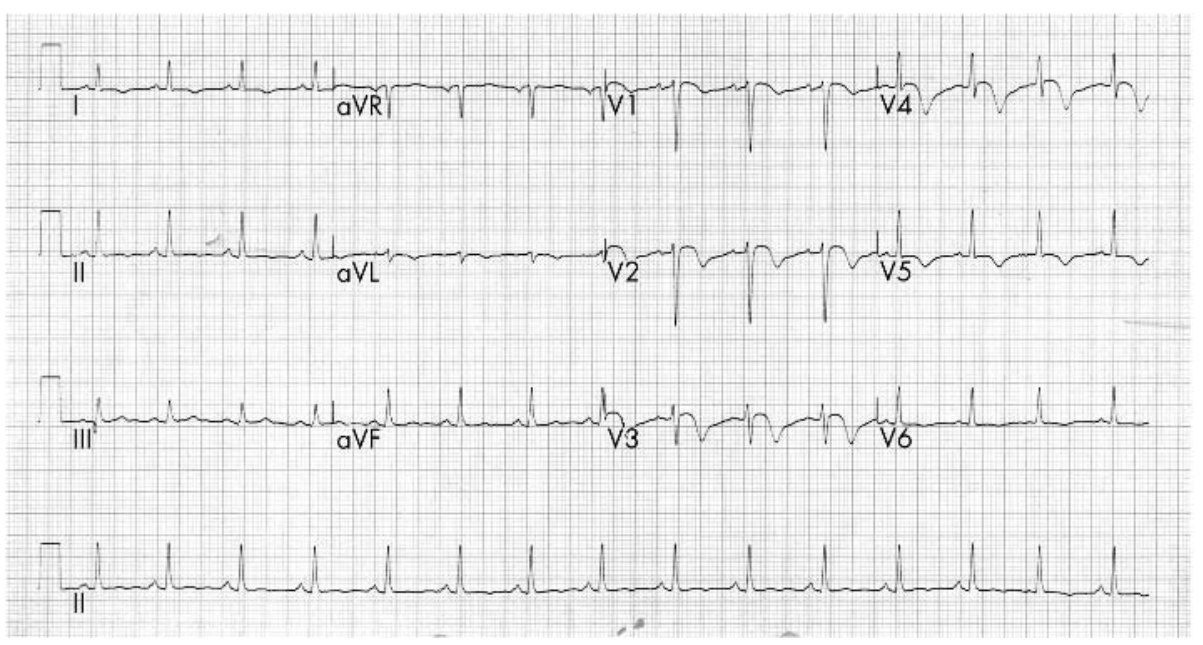

Figure 1 ECG at first presentation showing anterolateral T wave inversion. 


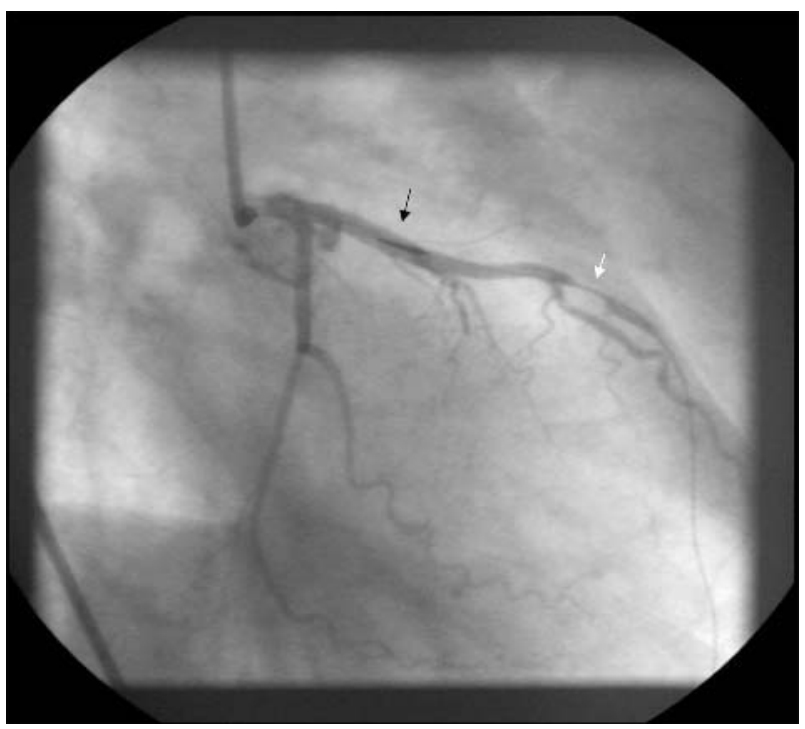

Figure 2 Diagnostic coronary angiogram during ergonovine provocation testing. The intravascular ultrasound probe (black arrow) lies at the site of an area of mild atheromatous disease in the left anterior descending artery. The area of induced focal spasm (white arrow) can be seen in the mid vessel.

to settle the symptoms pharmacologically. Despite these medical measures she continued to have chest pain with ECG changes, mostly in the early hours. After discussion with the patient, the decision was made to proceed to ergonovine provocation testing with a plan to stent the suspect area, namely the $20 \%$ atheromatous plaque in the LAD.

Before the provocation test, coronary vasodilator drugs were stopped (48 hours before) and a dextrose saline infusion was commenced overnight. Both the right femoral artery and the right femoral vein were cannulated with 6 French sheaths. A left Judkins 4 catheter was used to intubate the left main coronary artery and an IVUS catheter was introduced to the site of the mid-LAD lesion. This confirmed the presence of mural plaque at this site but identified no other lesions. Ergonovine $200 \mu \mathrm{g}$ was then given through the 6 French femoral venous sheath. After two minutes the patient had her usual pain and the ST segments became elevated in the chest leads. Coronary angiography showed a focal area of spasm of the LAD in its mid segment (fig 2). The site of provoked spasm was distal to and distinct from the area of mild atheromatous disease previously identified. A $3 \times 15 \mathrm{~mm}$ stent was deployed at the site of spasm. Following stent deployment the ergonovine provocation test was repeated with another dose of $200 \mu \mathrm{g}$. There were no further chest pain or ECG changes and no spasm on repeat angiography. The patient remained well after this procedure and was discharged, continuing to take clopidogrel and atorvastatin. She has been followed up at six and 12 months and remains symptom-free.

\section{DISCUSSION}

Most patients with symptomatic coronary spasm have a good prognosis $^{67}$ and respond well to drug treatments such as nitrates, ${ }^{8}$ calcium channel blockers, ${ }^{9} \beta$ blockers, ${ }^{10}$ or nicorandil. ${ }^{11}$ Not all patients settle with medical treatment. There is a group of patients who respond poorly to pharmacotherapy.$^{12}$ Coronary stenting in these patients does appear to be a safe and effective treatment option with risks similar to that of coronary intervention for other indications. ${ }^{1-4}$ The site of the focal spastic coronary segment is often associated with an area of coronary mural plaque disease. A previous description of this use of IVUS in this context reported the spastic segment to be invariably associated with an underlying subendothelial atheromatous plaque. ${ }^{5}$ Our case study suggests that this is not exclusively the case. In patients with severe recurrent coronary artery spasm refractory to pharmacotherapy, formal provocation testing should therefore be performed to identify a target coronary spastic segment for coronary stenting.

\section{Authors' affiliations}

T Azeem, D Adlam, A Gershlick, Department of Cardiology, Glenfield Hospital, Leicester, UK

Correspondence to: Dr David Adlam, Wellcome Trust Centre for Human Genetics, Roosvelt Drive, Oxford OX3 7BN, UK; davidadlam@doctors. org.uk

Accepted 23 February 2004

\section{REFERENCES}

1 Sueda S, Suzuki J, Watanbe K, et al. Comparative results of coronary intervention in patients with variant angina versus those with non-variant angina. Jpn Heart J 2001;42:657-67

2 Khatri S, Webb JG, Carere RG, et al. Stenting for coronary artery spasm. Catheter Cardiovasc Interv 2002;56:16-20.

3 Gaspardone A, Tomai F, Versaci F, et al. Coronary stent placement in patients with variant angina refractory to medical treatment. Am J Cardiol 1999;84:96-8.

4 Serrador A, Roman JA, Duran JM, et al. Successful treatment of vasospastic angina with a coronary stent. J Invasive Cardiol 2000;12:586-8.

5 Hong MK, Park SW, Lee CW, et al. Intravascular ultrasound findings of negative arterial remodelling at sites of focal coronary spasm in patients with vasospastic angina. Am Heart J 2000;140:395-401.

6 Scholl JM, Veau P, Benacerraf A, et al. Long-term prognosis of medically treated patients with vasospastic angina and no fixed significant coronary atherosclerosis. Am Heart J 1988;1 15:559-64.

7 Yasue $H$, Takizawa A, Nagao M, et al. Long-term prognosis for patients with variant angina and influential factors. Circulation 1988;78:1-9.

8 Ginsburg R, Lamb IH, Schroeder JS, et al. Randomized double-blind comparison of nifedipine and isosorbide dinitrate therapy in variant angina pectoris due to coronary artery spasm. Am Heart J 1982;103:44-8.

9 Chahine RA, Feldman RL, Giles TD, et al. Randomized placebo-controlled trial of amlodipine in vasospastic angina. Amlodipine study 160 group. J Am Col Cardiol 1993;21:1365-70.

10 Mulchary D, Crake T, Crean P, et al. Therapeutic implications of dynamic coronary stenosis in patients with single vessel coronary disease. Eur Heart $J$ $1991 ; 12: 514-9$.

11 Kurisu S, Kawagoe II, Ishihara M, et al. Usefulness of massive oral nicorandil in a patient with variant angina refractory to conventional treatment. Intern Med 2003:42:163-7.

12 Sueda S, Kohno H, Watanabe K, et al. Limitations of medical therapy in patients with pure coronary spastic angina. Chest 2003;123:380-6. 